\title{
High-Field Strong-Focusing Undulator Designs for X-Ray Linac Coherent Light Source (LCLS) Applications*
}

\author{
S. Cáspi ${ }^{\dagger}$, R. Schlueter ${ }^{\dagger}$, R. Talchyn \\ Stanford Linear Accelerator Center, Stanford, CA 94305, USA \\ !Lawrence Berkeley Laboratory, Berkeley, CA 94720 , USA
}

\begin{abstract}
Linac-driven X-Ray Free Electron Lasers (e.g.. Linac Coherent Light Sources (LCLSs)), operating on the principle of single-pass saturation in the Self-Amplified Spontaneous Emission (SASE) regime typically require multi-GeV beam energies and undulator lengths in excess of tens of meters to attain sufficient gain in the $1 \dot{A}-0.1 \dot{A}$ range. In this parameter regime, the undulator structure must provide: 1) field amplinudes $B_{0}$ in excess of IT within periods of $4 \mathrm{~cm}$ or less, 2) peak on-axis focusing gradients on the order of $30 T / m$, and 3 ) field quality in the $0.1 \%-0.3 \% \mathrm{range}$. In this paper we report on designs under consideration for a 4.5-1.5 A LCLS based on superconducting (SC), hybrid/PM, and pulsed-Cu technologies.
\end{abstract}

\section{INTRODUCTION}

In recent years, a multi-institutional study group has been considering the use of a portion of the $3 \mathrm{~km}$ S-band linac to drive a 4.5-1.5 $\dot{A}$ LCLS at the Stanford Linear Accelerator Center (SLAC) [1]. The idea is to accelerate and compress a low-normalized-emittance beam from a laser-driven photocathode if gun to peak currents in the $2.5-7.5 \mathrm{kA}$ range and emittances approximating $\varepsilon \leq \lambda / 4 \pi$ (where $\lambda$ is the output wavelength), and then induce gain saturation by passing the beam through a sufficiently long undulator with superimposed strong focusing. In modeling lasing performance at 4.5-1.5 $\dot{\AA}$. undulator periods in the range $2 \mathrm{~cm}<\lambda_{\mu}<4 \mathrm{~cm}, K$ parameters ( $K=0.934 \lambda_{u} B_{0}[T]$ ) in the range $2.5<K<4$, and quadrupole focusing with gradients ranging from $25-75 \mathrm{~T} / \mathrm{m}$, have been studied [2]. In vjew of the single-pass mode of operation and $120 \mathrm{~Hz}$ repetition rate of the linac, a wide range of undulator technologies, a number of which are depicted in Fig. 1, can in principie satisfy the given field and period requirements. In considering these technologies, a number of practical factors must be taken into account. These include: 1) fabrication cost (proportional to length); 2) operating cost; 3) attainable field quality; 4) tunability; 5) means for implementing strong focusing: and 6) stability in the linac environment.

In outlining a research and development program expected to culminate in the construction of a 4.5-1.5 A LCLS at SLAC, technologies that promise the highest on-axis undulator fields (viz., the shortest suructures) and focusing gradients have been emphasized. Thus, despite a strong base of experience in E\&M (DC) technology at LLNL [3] and a prior study of pure PM structures for a longer-wavelength LCLS [4], the r\&d

\footnotetext{
"Wart supperied is purt by the Departmens of Enetgy Offices of Bssic Enetgy Sciesces

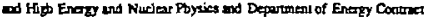
DE-ACO2-76SFDOS1S
}

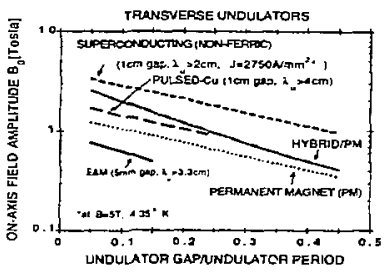

Figure 1. On-axis field performance of selected technologies.

effor at SLAC is carrently centered on (non-ferric) SC [5], hybrid/PM [6], and pulsed-Cu [7] technologies, with a practical emphasis on the first two. To date. ferric SC technology $[8,9]$ has not been pursued due to as-yet-unresolved methods for atlaining the desired focusing. In this paper we report on the following design studies currently underway in the three cited technologies: I) a bifilar helical SC undulator $[10\}$; 2) a new hybrid/PM design with monogenic dipole/focesing fields[1 l]: 3) a weakly-focusing hybridPM design with superimposed strong PM focusing [12,13]; and 4) a pulsed-Cu design. For definiteness, we restrict each design to $\lambda=1.5 \AA$ and an electron beam energy of $14.3 \mathrm{GeV}(\gamma \equiv 28,000)$. The (transverse) undulator period is then $\lambda_{u}[\mathrm{~cm}] \equiv 24 /\left(1+K^{2} / 2\right)$. with $K \rightarrow 2^{1 / 2} K$ for a helical structure.

\section{SC BIFILAR HELICAL DESIGN}

In the past two decades high-current-density accelerator magnets up to $17 \mathrm{~m}$ long have been built, achieving 4-10 Tesla central fields with ertor levels in the $10^{-4}$ range. Made of superconducting NbTi and nested in a two-layer "cosine-theta" fashion, these electromagnets employ "Rutherford" cable. include a large return iron yoke, and are restrained with a thick sinuctural shel] [14]. Operating at temperatures between 1.8 $4.2 \mathrm{~K}$ and at currents of several thousand Amperes, these magnets atain a stored energy of several tens of $\mathrm{kJ} / \mathrm{m}$ and require an insulator that can withstand several $\mathrm{kV}$. With a current-carrying capacity of $3000 \mathrm{~A} / \mathrm{mm}^{2}$ (at 5 Tesla), these components require special attention to ensure their safety in the event of a quench.

In contrast, a non-ferpic SC helical undulator will most likely be: 1) lower-field (viz., 2-3 Tesla), 2) currentdominated, 4) small, and 5) self-protecting. A single wire strand will replace the cable while maintaining the "cosinetheta" configuration. On the other hand, since a SC device can 
be current and fieid limited, field non-linearities that are coramon in helical magnets are likely to cause the field at the conductor to increase at the expense of a reduced central field. Keeping the non-linearities as low as possible will require the use of magnets whose ratio of circumference to period is small (on the order of 1 or less), mitigating parasitic effects that can strongly aiter the purity of the dipole field [15]. An undulator with a period of $27 \mathrm{~mm}$ would consequently imply the use of a coil with a diameter $\leq 8 \mathrm{~mm}$. In a recent conceprual study a single SSC-type strand [16] has been used to structure a 2-layer helical bifilar magnet in a geontetry designed to minimize the sextupole component (see Fig. 2). This $(0.72 \mathrm{~mm}$ diameter) wire - with a Cu/SC ratio of 1.3:1 carries about $900 \mathrm{~A}$ and generates a central field of 2 Tesla. Replacing it with an Arificial Pinning Center (APC) wire, which has a greater current carrying capacity at low fields (e.g., $5000 \mathrm{~A} / \mathrm{mm}^{2}$ at 3.5 Tesla), the maximum central field could be made to approach 2.5 Tesla..

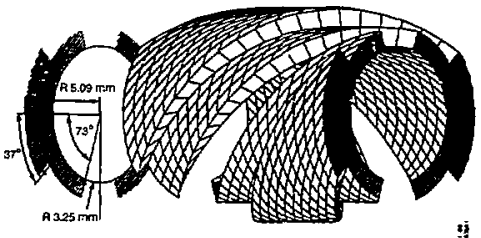

Figure 2. SC bifilar winding design with low field harmonics.

With regard to magnet safety and protection. present estimates are that with a low operating stored energy (on the order of $200 \mathrm{~J} / \mathrm{m}$ ) [17], and with a high current density in the copper $\left(5000 \mathrm{~A} / \mathrm{mm}^{2}\right)$, quench propagation may be fast and the magnet may dissipate its energy in about $13 \mathrm{~ms}$ while generating only several tens of Volts. To test the selfprotection of the windings under these conditions, as well as to investigate issues of field quality, SC focusing, charging time. and specific quenching mechanisns, the construction of a short LCLS prototype is planned within the coming year.

\section{HYBRID/PM SINGLE-STRUCTURE DESIGN}

One hybrid/PM LCLS design under study is a novel strong-focusing configuration featuring vanadium permendur poles excited by $\mathrm{NdFe} / \mathrm{B}$ permanent magnets, sections of which have poles that are alternately tilted in the $+/$ - transverse direction with respect to the midplane and simultaneously wedge-shaped, as viewed from above. For example, such a device with a $4 \mathrm{~cm}$ period, a $0.6 \mathrm{~cm}$ gap on-center, a $\pm 8.6^{\circ} \mathrm{wh}$, and $a \pm 10.7^{\circ}$ wedge could provide a $45 \mathrm{~T} / \mathrm{m}$ gradient and an on-axis field strength of $0.97 \mathrm{~T} ; \Rightarrow \mathrm{K}=4$. Minimum/maximum gap at transverse position $x= \pm 0.66 \mathrm{~cm}$ would be $0.4 / 0.8 \mathrm{~cm}$. Pole thickness at $x= \pm 0.66 \mathrm{~cm}$ is $1.0 \pm 0.25 \mathrm{~cm}$. The iron pole pieces shape the field, affording better design quality than is possible with a pure PM device at this small gap.

The choice of simultaneous pole tilt with respect to the midplane and nonuniform pole thickness follows from a 3-D analysis of the idcal pole shape for the superposition of fields from an undulator and a quadrupole.. Let $(x, y, z)$ be the horizontal, vertical, and axial directions. Define complex variables $w^{\prime} \equiv Z+i y$ and $z=x+i y$. The desired wiggle field and focusing field are, respectively, $B_{\text {wig }}(w)=i B_{0} \cos h w$ and $B_{f a c}^{*}(z)=i 2 a z$, where $k \equiv 2 \pi / \lambda_{4}$ and $a$ is a (focusingstrength) constant. The corresponding scalar potential in the gap is given by $V_{S D}=V_{h i g}+V_{f o c}=\left(B_{0} / k\right) \sinh k y \cos k Z+2 a x$. A contour along which $V$ is constant is an equi-scalar potential surface to which the magnetic field is orthogonal. Choosing the boundary of the vanadium permendur pole, whose permeability is effectively infinite, to lie along a constant- $V$ contour specified by $Y=f\left(B_{0}, 2 a, \lambda_{u}, h\right)$, where $h$ is the halfgap, gives rise to the wiggle and focusing fields described jiove. The equi-scalar potential contour along the ideal pole surface passing through the point $(0, h, 0)$ is $V_{3 D}(0, h, 0)=\left(B_{0} / k\right) \sinh k h$. Thus, the ideal pole contour lies along the surface defined by

$$
1=\cos k Z\left(\frac{\sinh k g}{\sinh k h}\right)+\left(\frac{y}{h}\right)\left(\frac{x}{8}\right)\left(\frac{k h}{\sinh k h}\right) .
$$

where $g \equiv B_{0} / 2 a$. The complicated 3-D curved pole shape is approximated by the canted, wedged pole baving flat surfaces described at the beginning of this section.. This practical design has the desirable feature that the PM material placed between poles remains a simple cuboid. TOSCA [11] modeling of the canted, wedged, flat-surfaced pole achieves very nearly the performance atiained in the ideal analylical design.

Hybrid technology is proven, and PM forces for the LCLS design are small. Modular construction of a $55 \mathrm{~m}$-long device is convenient, possibly bejng in-vacuum. The PM cost for 1000 periods, each consisting of four $1 \mathrm{~cm} \times 3 \mathrm{~cm} \times 3 \mathrm{~cm}$ blocks at $-\$ 4 / \mathrm{cm}^{3}$ is only $\$ 144.000$. Alternating gradient focusing can be achieved by having a $-0.5 \mathrm{~m}$-long focusing section, followed by "drift" and defocusing sections. The wiggle field is matched throughout the sections (see Fig. 3).

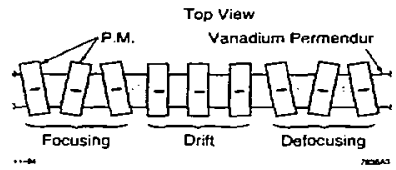

Figure 3. Wedged/canted hybrid/PM undulator section.

\section{HYBRID/PM SEPARATED-FUNCTION DESIGN}

A second hybrid/PM LCLS design uúlizes a conventional array of simple cuboid poles and $\mathrm{NdF} / \mathrm{B}$ magnets to generate a weakly-focusing undulator field, with strong quadrupole focusing provided by superimposed arrays of PM pieces. In one version of this design the PM pieces comprise simple block-pairs inserted into the gap from the sides [13]; in another version the PM pieces are thin strips (1-2 mm) arranged into planar quadrupoles [12] and affixed, along with Beam Position 
Monitors (BPMs), to the vacuum duct, which remains mechanically independent of the undulator structure [18]. Potential advantages of this approach include: 1) easier lateral access to the beam, 2) higher attainable undulator fields (1.2$1.4 \mathrm{~T}), 3$ ) amenability to undulator tuning with shunt plates. and 4) quadrupole field tuning with mechanical actuators.

\section{PULSED-CU DESIGN}

Based on prior work on pulsed-Cu undulator prototypes at LANL $[7,19]$, estimates of the operating parameters of a pulsed-Cu LCLS indicate that such a design, in principle, could be realized with existing ter' nology. For example, for a 30m structure operating at $120 \mathrm{~Hz}$, a Pulse Forming Network (PFN) would need to generate $1202 \mu$ current pulses (with tops sufficiently flat over a $0.2 \mu$ s interval) per second. For a tolal bifilar wire cross section of $0.25 \mathrm{~cm}^{2}$ and a resistance of $0.15 \Omega$, pulsing with a peak current of $50 \mathrm{kA}$ would require reak and average powers of $375 \mathrm{MW}$ and $90 \mathrm{~kW}$, respectively. As suggested by the cited research, prototype r\&d for the LCLS would need to focus on field quality issues stemming from: 1) impulsive and oscillatory stresses, 2) longer-term (irreversible) strains, and 3) themal loading.

\section{SUMMARY}

A summation of critical parameters and $r \& d$ areas associated with the undulator technologies described above is listed in Table L. Over the next two years the LCLS program

\begin{tabular}{|c|c|c|c|}
\hline Table 1 & SC & Hybrid/PM & Polsed-Cu \\
\hline Minimal Period $[\mathrm{cm}]$ & 2 & 3 & 2 \\
\hline Sat Length $[\mathrm{m}]$ & 30 & 55 & 30 \\
\hline Minimal Gap [mm] & 6 & 6 & 6 \\
\hline $\mathrm{K}$ at Minimal Period & -3.5 & -3.5 & -3.5 \\
\hline Focusing Methods & SC, PM & $\mathrm{PM}_{\mathrm{PS}}^{\mathrm{d}}$ & Pulsed, PM \\
\hline$\Delta \mathrm{B} / \mathrm{B}$ & $\begin{array}{l}-0.01 \% \\
\text { (in dipoles) }\end{array}$ & $\begin{array}{c}-0.2 \% \\
\text { (at 3rd gn. } \\
\text { sources) }\end{array}$ & $\begin{array}{c}>2 \% \\
\text { (attained at } \\
\text { LANL) }\end{array}$ \\
\hline Advantages & Shortest & $\begin{array}{l}\text { Proyen } \\
\text { Technology }\end{array}$ & $\begin{array}{l}\text { Short, No } \\
\text { Rad. Damage }\end{array}$ \\
\hline $\begin{array}{c}\text { Potential Problems \& } \\
\text { Engineering Issues }\end{array}$ & $\begin{array}{l}\text { Tolerances } \\
\text { Quenching } \\
\text { Rise Time }\end{array}$ & Damage & $\begin{array}{l}\text { Field Quality } \\
\text { Mech\&'Thm. } \\
\text { PFN }\end{array}$ \\
\hline
\end{tabular}

plans to address these issues, either at SLAC or in collaboration with laboratories specializing in the individual technologies. Problems common to all technologies, such as, e.g., undulator modularization [2],22], field metrology, and field and e-beam alignment strategies will atso be addressed.

\section{ACKNOWLEDGMENTS}

The authors would like to thank the members of the LCLS research group, in particular Klaus Halbach. Claudio Pellegrini, Roger Warten, and Herman Winick for their valuable critical and conceptual support.

\section{REFERENCES}

[1] R. Tatchyn, K Bane, R. Boyce, G. Loew, R. Miller, H.-D. Nuhn, D. Palmer, J. Paterson, T. Raubenheimer, J. Seeman, H. Wisick, D. Yeremian, C. Pellegrini, J. Rosenzweig, G. Travish, D. Prosniz, E. T. Scharlegann, S. Caspi, W. Fawley, K. Halbach. K.-J. Kim, R. Sch]ueter, M. Xie, R. Bonifacio, L. De Salvo, P. Pjerini, "Prospects for High Power Linac Coherent Light Source (LCLS) Development in the $100 \mathrm{~mm}-0.1 \mathrm{~mm}$ Wavelengh Range," presented at the 4th International X-Ray Laser Colloquium, Williamsburg, VA, May 16-20, 1994.

12] H.-D. Nuhn, E. T. Scharlemann. W. M. Fawley, and R. Schlueter, "Alignment and Magnet Error Tolerances for the LCLS X-Ray FEL," this conference, - FAA17.

[3] G. A. Deis, M. J. Bums, T. C. Christensen, F. E. Coffield B. Kulke. D. Prosnitz, E T. Scharlemann, and K. Halbach IEEE Trans. Mag. 24(2) 986(1988).

[4] R. Tatcbyn, R. Boyce, K. Halbach. H.-D. Nuhn, J. Seeman, H. Winick, and C. Pellegrini, "Design Considerations for a 60 Meter Pure Permanent Magnet Undulator for the SLA.C Linac Coherent Light Source (LCLS)," Proc. IEEE Particle Accelerator Conference, IEEE Cat. No. 93CH3279-7, pp, 1608-1610.

[5] L. R. Elias and J. M. Madey, Rev. Sci. Instrum. 50(11), $1335(1975)$.

[6] K. Halbach, J, Appl. Phys. 57(8). Part IA, 3605(1985).

[7] R. W. Warren and C. M. Fortgang, Nucl. Instrum. Meth.A331, 706(1993).

[8] I. Ben-Zvi. R. Fernow, J. Gallardo, G. Ingold, W. Sampson, and M. Woodle, Nucl. Instrum. Meth. A318, $781(1992)$.

[9] S. C. Gotischalk, A. L. Pindroh, D. C. Quimby, K. E. Robinson, and J. M. Slater, Nucl. Instrum. Meth. A304, 732(1991).

[10] S. Caspi, "A Superconducting Helical Wiggler for Short Wavelength FELs," LB1D-2052, SC-MAG-475, September 1994.

[11] R. D. Schlueter, Nucl. Instrum. Moth. A358, 44(1995).

[12]R. Tatchyn, Nucl.. Instrum. Meth. A341, 449(1994).

[13]A. A. Variolomeev, V. V. Gubankov, A. H. Hairetdinov, S. N. Ivanchenkov, A. S. Khlebnikov, N. S. Osmanov, and S. V. Tolmachev, Nucl. Instrum. Meth. A358. 70(1995).

[14] D. Dell'Orco, S. Caspi, J. O'Neill, A. Liezzke, R. Scanlan, C. E. Taylor, and A. Wandesforde. IEEE Trans. Appl. Superconduct. 3(1), 637(1993).

[15] S. Caspi, "Magnetic Field Components in a Sinusoidally Varying Helical Wiggler," LBL-35928, SC-MAG-464, July 1994.

[16] S. Caspi, "Magnetic Field Components in a Helical Dipole wiggler with Thick Windings." LBID-2048, SC-MAG472, September 1994.

[17] S. Caspi, "Stored Energy in a Helical Wiggier," LBID2051, SC-MAG-474، September 1994.

[18]D. C. Quimb\%, S. C. Gottschalk, F. E. James, K. E. Robinson, J. M. Slater., and A. S. Valla, Nucl. Instrum. Meth. A285, 28 i(1989).

[19]C. M. Forgang and R. W. Warren, Nucl. Instrum, Meth. A341, 436(1994); R. Warten, private communication.

[20]W. V. Hassenzahi, T. M. Jenkins, Y. Namito. W. R. Nelson, and W. P. Swanson, Nucl. Instrum. Meth. A291, 378(1990).

[21] K. E. Robinson, D. C. Quimby, and J. M. Slater, IEEE Jour. Quant. Electr., QE-23, 9, 1497(1987).

[22]K.-J. Kim and M. Xie, "Effects of Wiggler Interruption on LCLS Performance, CBP Tech. Note-77, March 1995. 


\section{DISCLAMMER}

This report was prepared as an account of work sponsored by an agency of the United States Government. Neither tile United States Government oor any agency thereof, nor any of their employees, makes any warranty, exptess or implied, of assumes any legal liability or responsibility for the accuracy, completeness, or usefulness of any information, apparatus, product, of process disclosed, or represents that its use would not infringe privalely owned rights. Reference herein to any specific commercial product, process, or service by trade name, trademark, manulacturer, or otherwise does not necessarily constitute of imply its endorsement, recommendation, or favoring by the United States Government or any agency thereol. The views and opinions of authors expressed herein do not necessarily state or reflect those of the United States Governmeat or any agency thereof. 